\title{
LA-UR-17-21049
}

Approved for public release; distribution is unlimited.

Title: $\quad$ Lockout/Tagout for FODs \& RLMs Self-Study 30140

Author(s): $\quad$ Singledecker, Amalia

Intended for: Training

Issued: $\quad$ 2017-02-09 
Disclaimer:

Los Alamos National Laboratory, an affirmative action/equal opportunity employer, is operated by the Los Alamos National Security, LLC for the National Nuclear Security Administration of the U.S. Department of Energy under contract DE-AC52-06NA25396. By approving this article, the publisher recognizes that the U.S. Government retains nonexclusive, royalty-free license to publish or reproduce the published form of this contribution, or to allow others to do so, for U.S. Government purposes. Los Alamos National Laboratory requests that the publisher identify this article as work performed under the auspices of the U.S. Department of Energy. Los Alamos National Laboratory strongly supports academic freedom and a researcher's right to publish; as an institution, however, the Laboratory does not endorse the viewpoint of a publication or guarantee its technical correctness. 


\section{Lockout/Tagout for FODs \& RLMs Self-Study 30140}

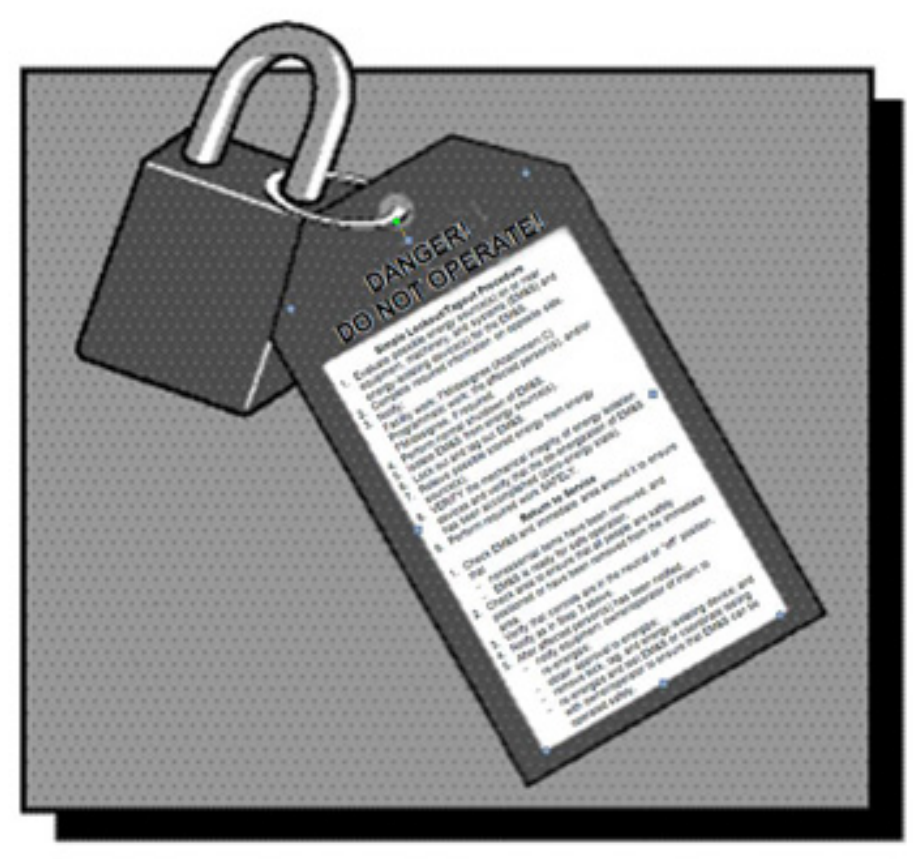

\section{February 2017}

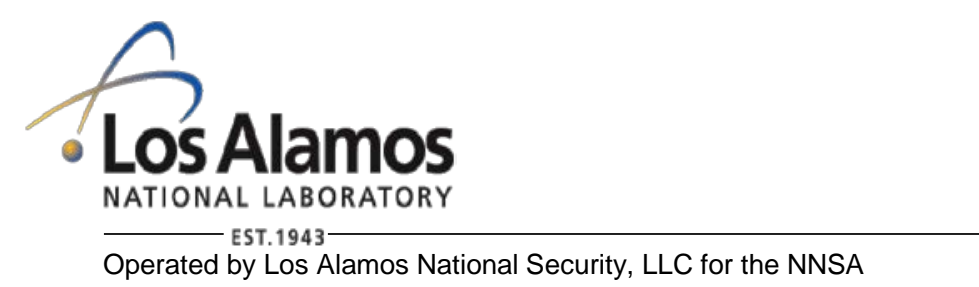


This training course was prepared by Los Alamos National Security, LLC (LANS) under Contract DE-AC52-06NA25396 with the U.S. Department of Energy, National Nuclear Security Administration (DOE/NNSA). All rights in the material are reserved by DOE and LANS pursuant to the contract. This training course is presented with the understanding that the information and materials provided were developed based on specific circumstances present at the Los Alamos National Laboratory at the time of publication. Those circumstances may or may not be similar to conditions present at other locations represented by participants in this course. The course materials and information will need to be adapted accordingly. NEITHER THE DOE/NNSA, NOR LANS, NOR ANY OF THEIR EMPLOYEES, MAKES ANY WARRANTY, EXPRESS OR IMPLIED, OR ASSUMES ANY LEGAL LIABILITY OR RESPONSIBILITY FOR THE ACCURACY, COMPLETENESS, OR USEFULNESS OF ANY INFORMATION, APPARATUS, PRODUCT, OR PROCESS DISCLOSED AND WILL NOT BE LIABLE FOR DIRECT OR INDIRECT DAMAGES RESULTING FROM USE OF THIS MATERIAL.

\title{
Institutional Training Services Group Leader \\ Cindy Dutro
}

Instructional Designer

Phill Grogin, Amalia Singledecker

\author{
Technical Advisor \\ John Urban \\ Editor/Compositor \\ Lisa Rothrock \\ Course 30140 \\ February 2017 \\ LA-UR-17-
}

Controlled Document Number: LockoutTagout_FODsRLMs_30140_SS,R1.0 


\section{Contents}

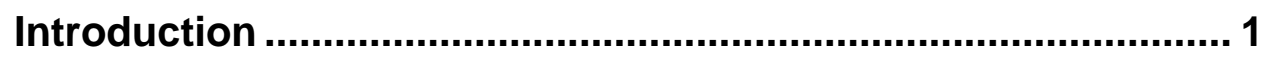

Course Overview and Objectives ....................................... 1

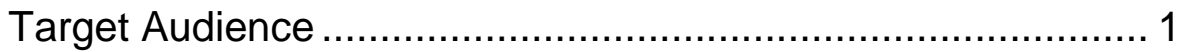

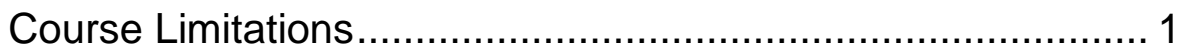

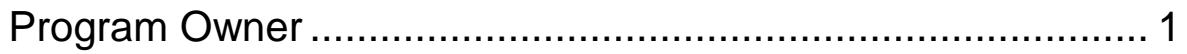

Module 1: Lockout/Tagout Drivers and Definitions .................... 3

Module Objectives .............................................................. 3

What Is Lockout/Tagout? .................................................... 3

When Is Lockout/Tagout Used? ............................................ 4

Who Must Use LANL Lockout/Tagout? ................................ 4

Documents that Address Lockout/Tagout............................... 4

Lockout/Tagout Definitions and Acronyms ............................ 6

Module 2: Hazardous Energy and Isolation Devices .............. 10

Module Overview and Objectives ................................... 10

Energy Types .................................................................. 11

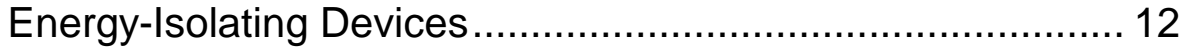

Lockout Devices .......................................................... 13

Lesson Learned................................................................... 14

Module 3: Roles and Responsibilities...................................... 15

Module Objective....................................................... 15

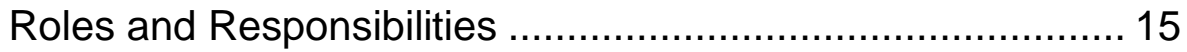

Module 4: Lockout/Tagout Attachments and Procedures....... 20

Module Overview and Objectives ........................................ 20

LANL Lockout/Tagout Attachments and Uses....................... 20

Lockout/Tagout Procedures-Simple or Complex Energy

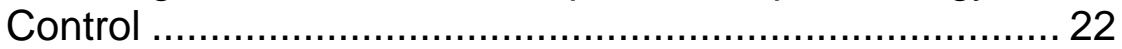

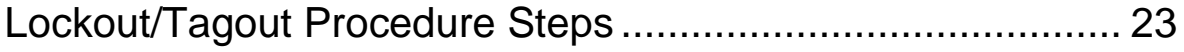

Lockout/Tagout Crosswalk .............................................. 29

Module 5: Lockout/Tagout Special Situations.......................... 30

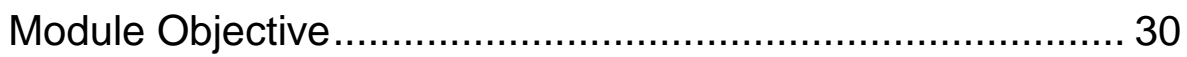

Lockout/Tagout Special Situations ….................................. 30 
Module 6: Lockout/Tagout Applicability ................................. 36

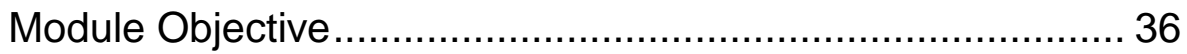

Activities for Which Lockout/Tagout Is NOT Applicable.......... 36

Sources That Are NOT Considered Hazardous Energy ......... 38

Module 7: Lockout/Tagout Training and Inspections .............. 39

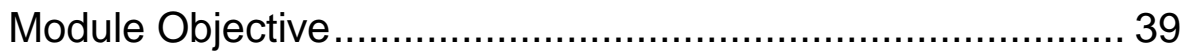

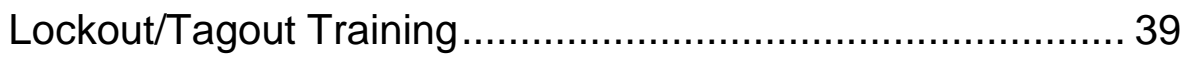

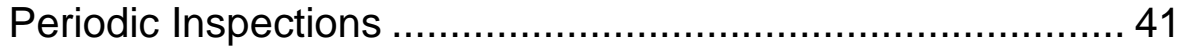

Appendix A: Lockout/Tagout Tag............................................ 42

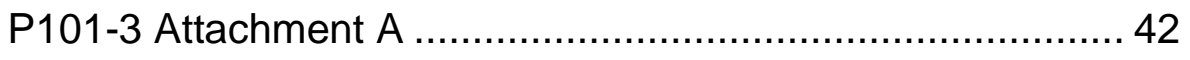

Appendix B: Lockout/Tagout Orders ..................................... 42 


\section{Introduction}

\section{Course Overview and Objectives}

Lockout/tagout (LO/TO) is used to disable machinery or equipment and to control potentially hazardous energy while service or maintenance is being performed. This course, Lockout/Tagout for FODs \& RLMs Self-Study (30140), is designed to introduce facility operations directors (FODs) and responsible line managers (RLMs) to changes in the Los Alamos National Laboratory (LANL) procedure for the lockout and tagout of hazardous energy.

When you have completed this course, you will be able to

- recognize hazardous energy types,

- recognize energy-isolating devices and lockout devices,

- identify the responsibilities of key personnel and organizations involved in the LO/TO procedure,

- recognize LO/TO documentation forms and records, and

- recognize hazardous energy control procedures.

\section{Target Audience}

This training applies to all LANL FODs and RLMs supervising workers who use locks/tags for hazardous energy control (HEC) for personnel safety at LANL or who have other responsibilities for HEC as defined in Procedure (P) 101-3, Lockout/Tagout for Hazardous Energy Control, and who have previously completed LANL LO/TO training requirements.

\section{Course Limitations}

Site-specific training may be required in addition to this course. This training is not a substitute for the required reading of P101-3.

\section{Program Owner}

This course was developed under the direction and technical oversight of Occupational Safety and Health-Industrial Safety and Hygiene (OSH-ISH), the functional program owner for this training. 


\section{About This Self-Study Course}

Lockout/Tagout for FODs \& RLMs Self-Study (course 30140) consists of an introduction, seven modules, Appendix A, Appendix $B$, and a quiz. To receive credit in UTrain for completing this course, you must score $80 \%$ or better on the 10 -question quiz. Directions for initiating the quiz are appended to the end of this training manual. 


\section{Module 1: Lockout/Tagout Drivers and Definitions}

\section{Module Objectives}

When you have completed this module, you will be able to recognize

- definitions associated with lockout/tagout (LO/TO),

- when and by whom LO/TO is used, and

- drivers that address LO/TO

\section{What Is Lockout/Tagout?}

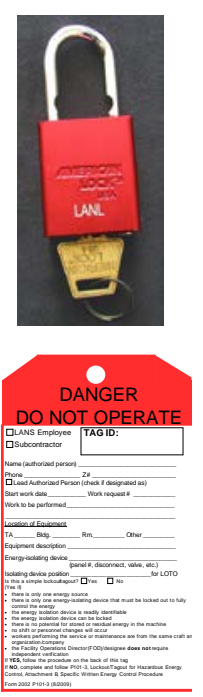

LO/TO is used to disable machinery or equipment and to control potentially hazardous energy while service or maintenance is being performed. At its simplest, LO/TO is the placement of a lock and tag on an energy-isolating device to ensure that the equipment being controlled cannot be operated until the lock is removed.

Note the following key elements of LO/TO:

- LO/TO is performed by trained and qualified "authorized workers" who follow strict procedures to control hazardous energy.

- Authorized workers must interact with equipment owners, FODs, RLMs, and subject matter experts (SMEs), all of whom have special responsibilities in the Lockout/Tagout Program.

\section{What Is Tagout?}

\section{If you CAN lock out, you MUST lock out!}

Tagout is the placement of ONLY a LANL-approved tag, without a lock, on an energy-isolating device to indicate that the energyisolating device and the equipment being controlled may not be operated until the tag is removed. Use of a tag requires only those additional physical controls that provide worker protection equivalent to a lockout.

Note: If an energy-isolating device is physically capable of being locked out, the authorized worker must use a lock and the LO/TO process rather than the tag-only option. 


\section{When Is Lockout/Tagout Used?}

Authorized workers performing LO/TO must lock and tag the equipment energy-isolating device(s) with a LANL lock and tag when

- they are performing any maintenance or service on machines, systems, and equipment; and

- any person could be injured if the equipment unexpectedly energizes or starts or if stored energy or toxic material is unexpectedly released.

Note: If an energy-isolating device cannot physically be locked out, a LO/TO tag must be used with additional physical controls that provide worker protection that is equivalent to a lockout.

\section{Who Must Use LANL Lockout/Tagout?}

LANL LO/TO applies to all LANL workers including subcontractors who use locks/tags for hazardous energy control for personnel safety.

Subcontractors engaged in moderate, high-hazard, or construction work must follow the requirements of Procedure $(P)$ 101-3, Lockout/Tagout for Hazardous Energy Control, including the required training.

High-hazard and construction, maintenance, installation, or vendor subcontractor personnel must follow the requirements of P101-3, including the required training, if their work could potentially expose them to hazardous energy.

$\mathrm{P} 101-3$ is referenced in the Exhibit $\mathrm{F}$ of such subcontracts. The current requirements for subcontractors are found in P101-12, ES\&H Requirements for Subcontractors.

\section{Documents that Address Lockout/Tagout}

\section{Occupational Safety and Health Administration (OSHA) Standards for Lockout/Tagout}

OSHA 29 Code of Federal Regulations (CFR) 1910.147, Control of Hazardous Energy (Lockout/Tagout), is meant to protect workers from the unexpected startup of machines or equipment or the unexpected release of hazardous energy during service or maintenance. 
See Module 2 for information about sources of hazardous energy.
OSHA 29 CFR 1910.147 applies to all sources of hazardous energy, and requires LANL to

- identify the practices and procedures needed to shut down and lock out machines and equipment,

- train workers in their role(s) in the LO/TO program, and

- periodically inspect the hazardous energy control program.

OSHA 29 CFR 1910.147 requires that, in general, before service or maintenance is performed on machines or equipment,

- the machines or equipment be turned off and disconnected from the energy source, and

- the energy-isolating device be either locked or tagged out.

Note: 29 CFR 1910.147 specifically excludes some electrical hazards. See Module 5 for more details.

\section{LANL Lockout/Tagout Procedure}

LANL P101-3, Lockout/Tagout for Hazardous Energy Control, is LANL's energy control procedure. P101-3 provides information on

- the purpose and scope of LO/TO for hazardous energy control,

- terms used in LO/TO operations,

- responsibilities of workers and organizations,

- HEC procedures and forms, and

- training and periodic inspections.

The requirements in P101-3 apply to all sources of energy when they constitute a hazard to workers. The LO/TO Program applies to HEC during servicing and/or maintenance of all machines, systems, and equipment.

The requirements in P101-3 apply to all LANL workers, managers, and subcontractors who use HEC locks and tags for personnel safety at LANL or who have other responsibilities for HEC as defined in P101-3. 


\section{Lockout/Tagout Definitions and Acronyms}

\section{Definitions}

Affected worker-Any worker whose job requires him/her to operate or use equipment on which servicing or maintenance is being performed under LO/TO or whose job requires him/her to work in an area in which such servicing or maintenance is being performed or where equipment operation could pose a danger. Affected workers can become authorized workers.

Authorized worker-Any worker who locks out and/or tags out equipment to perform servicing or maintenance on that equipment or to prohibit operation of equipment that could pose danger. Authorized workers will complete LO/TO training and be authorized by their RLMs.

Disconnecting devices (Disconnecting Means per OSHA)—A device, group of devices, or other means by which the conductors of a circuit can be disconnected from their source of supply.

Electrical lockout/tagout -A LO/TO where an electrical component, such as a breaker or disconnect switch, is the energy-isolating device or one of the energy-isolating devices.

Energy control procedure-A series of actions conducted in a prescribed order specifically designed to prevent the release of hazardous energy or startup of a machine or equipment during maintenance or repair. The purpose of the procedure is to guide the worker through the LO/TO process.

Energy-isolating device-A mechanical device that physically prevents the transmission or release of energy. Examples are manually operated electrical circuit breakers, disconnect switches, slide gates, slip blinds, line valves, blocks, and any similar device used to block or isolate energy. Push buttons, selector switches, interlocks, and other control circuit-type devices are NOT energy-isolating devices.

Energy isolation point-The location(s) on equipment or machinery that can physically be locked out to control the unexpected release of hazardous energy.

Energy source/type-Any source of electrical, mechanical, hydraulic/pneumatic, chemical, thermal, radiation, or other energy.

Equipment and machinery_A broad term that encompasses all types of equipment, including process equipment such as piping systems.

Exclusive control-The authority and position a worker continuously has to prevent other individuals from reenergizing a machine, circuit, system, or component. When used relative to cord-and-plug-connected electrical equipment, for which exposure to hazards of unexpected energization or startup of the equipment is controlled by the unplugging of the equipment from the energy source, the plug is under the exclusive control of the worker performing the servicing or maintenance.

Group lockout/tagout-A LO/TO where two or more authorized workers, regardless of their occupation or craft, lock out and tag out the same equipment to perform servicing or maintenance. 
Hazardous energy assessment-Identification of energy type(s), source(s), and the means of controlling the hazardous energy source(s) associated with equipment.

Independent verification-Where required, completed before initiation of work, independent verification is an action by a second authorized worker who will not be performing maintenance or servicing on the equipment or machine. Equipment or operations requiring independent verification are designated by the FOD/designee. Specific requirements for independent verification will be documented in a specific written procedure. Independent verification techniques and the actions required of the verifier are included in P315, Conduct of Operations Manual, Attachment 10, Independent Verification.

Lead authorized worker-A worker who is responsible for coordinating LO/TO activities for all members of a group LO/TO. The RLM appoints the lead authorized worker if all of the workers involved are from the same craft, company, or line organization. The FOD/designee appoints the lead authorized worker (with input from the RLMs) if the workers are from multiple crafts, companies, and/or line organizations.

Lock coordinator-A worker appointed by the FOD who assists in managing LO/TO within the facilities under the FODs jurisdiction. Lock coordinators are extensions of the FOD responsibility and authority when so designated.

Lockout/tagout (LO/TO) - The placement of a lock and tag on an energy-isolating device by an authorized worker in accordance with the requirements of this procedure to ensure that the equipment being controlled cannot be operated until the lock is removed.

LOITO procedure-The step-by-step procedures to achieve control of the hazardous energy. Attachment A, Simple Energy Control Procedure, Lockout/Tagout (LO/TO) Tag, and Attachment $\mathrm{B}, \mathrm{LO} / \mathrm{TO}$ Orders, are hazardous energy control procedures when filled out for a specific work activity or equipment.

Near-Working within the limited approach boundary as defined in NFPA 70E, Standard for Electrical Safety in the Workplace, Table 130.2.

Notification-An effective method of communication to affected workers before equipment is taken out of service or is locked out/tagged out, and upon completion of work before the equipment is returned to service.

Ownerloperator-An authorized worker who is responsible for controlling the status of equipment (specific breaker, specific equipment, etc.) in a defined area (a building, laboratory, etc.). The owner/operator will be the SME for equipment startup, shutdown, and isolation in the defined area. The FOD/designee will designate facility owners/operators in writing.

Responsible line manager (RLM) - The group leader (or equivalent LANL or subcontractor line manager) having responsibility, authority, and accountability for overall planning, validation, coordination, approval, execution, and closeout of a work activity. The RLM may delegate responsibility and authority, but not accountability, for fulfilling these roles. 
Rolling lockout - Use of a single lock with multiple tags by a worker to conduct a sequence of simple lockout operations when conducting maintenance on a group of co-located identical equipment having individual disconnects/isolation points.

Servicing and/or maintenance-Workplace activities, such as constructing, installing, setting up, adjusting, inspecting, modifying, and maintaining and/or servicing machines or equipment. These activities include lubricating, cleaning, or unjamming machines or equipment, changing a sample, changing a test configuration, or making adjustments where the worker may be exposed to physical harm from the unexpected energization or startup of the equipment or release of hazardous energy.

Shift/personnel change-Shift or personnel change occurs when a worker or workers leave the work because of reassignment or end of shift (change) and a worker (or workers) is coming on to continue the work. Specific procedures will be used to provide continuity of LO/TO protection through this transition period.

Simple Energy Control Procedure-The documented energy control procedure that does not require completion of a specific written energy control procedure because the equipment or machinery requiring LO/TO meets all the following requirements:

- there is only one energy source,

- there is only one energy-isolating device that must be locked out to fully control the energy,

- the energy-isolating device is readily identifiable,

- the energy-isolating device can be locked,

- there is no potential for stored or residual energy in the machine,

- NO shift or personnel changes will occur until work is completed, AND

- the FOD/designee does not require independent verification.

Specific Written Energy Control Procedure-An energy control procedure written by or with the help of the authorized worker(s) for a specific machine or equipment. See Attachment B, $L O / T O$ Orders. A separate written procedure that includes all of the information in Attachment B may be developed and used in place of Attachment B where necessary. In such cases, an Attachment B must still be used and attached for work to be authorized.

Subcontractor-A person performing work for LANL who is employed by a company providing products or services, or is an individual consultant, under a contract or subcontract with LANS.

Subject matter expert (SME) —A worker knowledgeable of equipment and its hazards through education, experience, or both. SMEs for equipment and machinery are designated by the FOD/designee or RLM and should be the owner/operator.

Tagout-The placement of a tag only on an energy-isolating device, in accordance with Attachment $\mathrm{B}$, to indicate that the energy-isolating device and equipment being controlled will not be operated until the tagout device is removed. 
Verification of isolation-Before starting work on machines or equipment that have been locked out/tagged out, the authorized worker will verify that isolation and de-energization of the machine or equipment have been accomplished.

Worker-LANS employees, subcontractor personnel, and visitors, if they could potentially be exposed to hazardous energy.

Zero-energy state-The lowest achievable energy state; the deenergized state of electrical energy sources achieved by discharging capacitive and inductive elements (absence of voltage and current) and blocking or totally releasing and preventing reaccumulation of mechanical energy (kinetic or potential).

\section{Acronyms}

CFR

EEWP

$E S \& H$

ESO

FOD

HEC

ISH

IV

IWD

LANL

LANS

LO/TO

MSS

NFPA

$\mathrm{OSH}$

OSHA

$\mathrm{P}$

PIC

RLM

SECP

SME

SWECP
Code of Federal Regulations

Energized Electrical Work Permit

environment, safety, and health

electrical safety officer

facility operations director

hazardous energy control

Industrial Safety and Hygiene (Group)

independent verification

integrated work document

Los Alamos National Laboratory

Los Alamos National Security (LLC)

lockout/tagout

Maintenance and Site Services

National Fire Protection Association

Occupational Safety and Health (Division)

Occupational Safety and Health Administration

procedure

person in charge

responsible line manager

Simple Energy Control Procedure

subject matter expert

Specific Written Energy Control Procedure 


\section{Module 2: Hazardous Energy and Isolation Devices}

\section{Module Overview and Objectives}

The purpose of LO/TO is to prevent the unexpected release of hazardous energy. Workers must identify types and sources of potentially hazardous energy before beginning maintenance or service activities on equipment. The proper control of hazardous energy sources can save your life and the lives of those nearby (affected workers).

When you have completed this module, you will be able to recognize

- types of hazardous energy,

- energy-isolating devices,

- lockout devices, and

- locks and tags approved for use in the LANL LO/TO program.

Lessons Learned: Employee Failed to Lock Out and Was Crushed in a Paper Baler

Employee \#1 entered a baler-forming cavity to unclog the baling press of excess paper. He failed to properly lock out the machine (he merely deactivated the hydropump switch). Another employee who had previously been called upon to operate the unit arrived at the machine and saw that it was in an operational mode. He activated the press to continue the operation. The machine appeared to be clogged so he shut it off and went to inspect the hopper well. He then saw employee \#1 who had been crushed to death by the ram when the press was activated by the second employee.

OSHA Accident Investigation Search \# 014491542 


\section{Energy Types}

The table below lists types of hazardous energy that may be encountered while working on (or in some cases, near) equipment.

\begin{tabular}{|c|c|c|}
\hline \multicolumn{3}{|c|}{ Types of Hazardous Energy } \\
\hline Energy & Source(s) & Examples \\
\hline Chemical & $\begin{array}{l}\text { A process or chemicals used } \\
\text { in a process }\end{array}$ & $\begin{array}{l}\text { Systems carrying chemicals through process piping } \\
\text { or in pressurized tanks } \\
\text { Large boiler systems }\end{array}$ \\
\hline Electrical & $\begin{array}{l}\text { Equipment that relates to or is } \\
\text { operated by electricity }\end{array}$ & $\begin{array}{l}\text { Transformers } \\
\text { Circuit breakers } \\
\text { Receptacles } \\
\text { Motors } \\
\text { Electrical conduit housing branch circuitry } \\
\text { Generators } \\
\text { Capacitors } \\
\text { Electromagnets } \\
\text { Power transmission lines }\end{array}$ \\
\hline $\begin{array}{l}\text { Hydraulic } \\
\text { pressure }\end{array}$ & $\begin{array}{l}\text { Operation of equipment by a } \\
\text { fluid that is under pressure }\end{array}$ & $\begin{array}{l}\text { Metal shear brake presses } \\
\text { Primary and secondary water lines } \\
\text { Masts that raise elevator platforms } \\
\text { Forks on a lift truck }\end{array}$ \\
\hline Mechanical & $\begin{array}{l}\text { Related to or produced by a } \\
\text { machine and/or gravitational } \\
\text { and kinetic forces }\end{array}$ & $\begin{array}{l}\text { Roll-up doors } \\
\text { Fans } \\
\text { Gates } \\
\text { Equipment gearing } \\
\end{array}$ \\
\hline $\begin{array}{l}\text { Pneumatic } \\
\text { pressure }\end{array}$ & $\begin{array}{l}\text { Typically involves } \\
\text { compressed air or gases }\end{array}$ & $\begin{array}{l}\text { Compressed air lines that power air ratchets } \\
\text { Super-heated steam lines } \\
\text { Natural gas lines }\end{array}$ \\
\hline Radiological & $\begin{array}{l}\text { lonizing radiation-related to } \\
\text { radiological materials } \\
\text { resulting from nuclear } \\
\text { reactions or charged particle } \\
\text { acceleration }\end{array}$ & $\begin{array}{l}\text { Radiological process piping } \\
\text { X-ray units, accelerators } \\
\text { Alpha, beta, gamma radiation } \\
\text { Neutrons }\end{array}$ \\
\hline Electromagnetic & Nonionizing radiation & $\begin{array}{l}\text { Lasers } \\
\text { Radio frequency (RF) } \\
\text { Microwave } \\
\text { Ultraviolet (UV) }\end{array}$ \\
\hline \multirow[t]{2}{*}{$\begin{array}{l}\text { Thermal } \\
\text { (temperature } \\
\text { extremes) }\end{array}$} & $\begin{array}{l}\text { The use, production, or } \\
\text { outcome of heat }\end{array}$ & $\begin{array}{l}\text { Hot water heaters } \\
\text { Space heaters } \\
\text { Steam lines } \\
\text { Compressors } \\
\text { Boilers } \\
\text { Gas convection heaters } \\
\text { Engine motors }\end{array}$ \\
\hline & Cryogens & Liquid nitrogen, liquid argon, liquid helium \\
\hline
\end{tabular}




\section{Energy-Isolating Devices}

An energy-isolating device is a mechanical device that physically prevents the transmission or release of energy. Examples are manually operated electricity circuit breakers, disconnect switches, valves, and blocks. Push buttons, selector switches, interlocks, and other control circuit-type devices are NOT energyisolating devices.

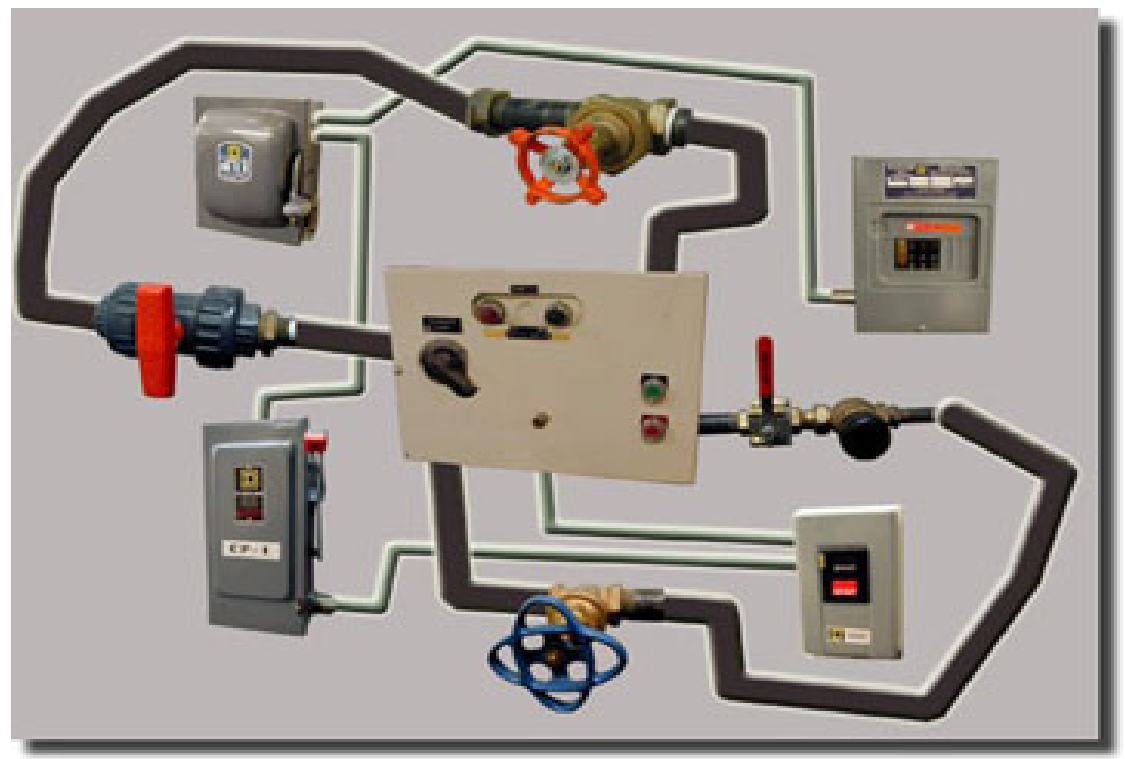

Energy-isolating devices

\section{Specification of and Providing Effective Lockout Devices}

FODs and equipment/system owners are responsible for identifying and providing effective lockout-adapting devices that work with the isolation devices (valves, switches, breakers, etc.) that are a part of their equipment or systems. Effective devices

- (when properly applied) prevent movement of the isolation device from a safe state to a hazardous state without the use of excessive manual force or tools,

- will accept a standard LANL-supplied HEC lock (and tag) that prevents removal of the device, and

- will last for the anticipated duration of the lockout in the environment in which they are to be used.

Note: The Maintenance and Site Services (MSS) webpage lists FOD contacts and information about locking devices. 


\section{Lockout Devices}

A lockout device uses a positive means of holding an energy-isolating device in the safe position. Hardware such as locks, blank flanges, slip blinds, chains, clamshell valve handle locks, hasps, and plug protectors are lockout devices. Locks (and tags) for HEC will NOT be used for any other purpose.

The ONLY lock that can be used for LO/TO at LANL is the red Model 1105 American Lock (or the Master Lock equivalent). This lock (shown at right) can be purchased only from LANLspecified providers.
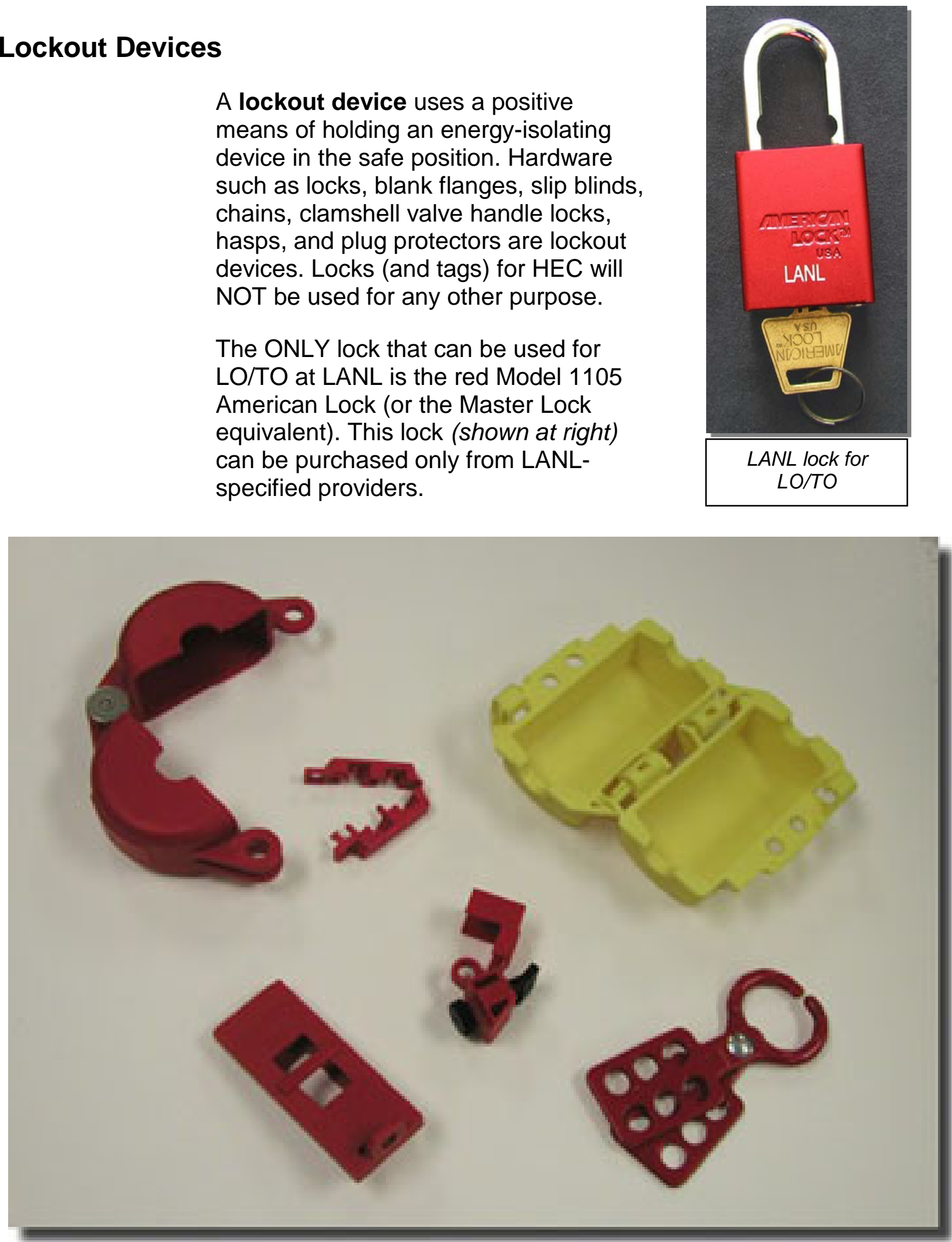

Lockout devices 


\section{Lesson Learned}

\section{Failure to Identify Secondary Energy Source Results in Explosion}

In October 2008, at Brookhaven National Laboratory, a leak of propane gas from a backup engine in a well house led to an explosion that demolished the well house. At approximately 3:00 p.m., a mechanic was performing preventive maintenance on a propane-powered backup engine in a well house. To access the wire terminals in the engine control panel, the mechanic removed the ignition slide switch and left it dangling on the side of the engine. After confirming that the system was working, he tried to shut down the engine by turning off the ignition switch, but the engine continued to run. He determined that replacement parts were needed to repair the engine.

Since it was close to the end of his shift, the mechanic decided to lock out/tag out the engine. He removed the negative terminal from the battery and attached a red LOTO tag to the still dangling ignition switch using a tie-wrap-type connector. He cinched the tie wrap with the lockout/tagout tag in front of the switch, blocking his view of the switch's position, and then left the building. At approximately 9:35 p.m., an explosion destroyed the well house. Fortunately, there were no injuries.

An investigation of the accident indicated the following:

- The ignition slide switch was found in the "RUN" position after the explosion. The investigation committee determined that the mechanic moved the slide switch to the "RUN" position while attaching the lockout/tagout tag. This action allowed the battery charger to power the ignition, opening the propane gas solenoid valve and allowing the engine air intake system (and eventually the room) to fill with propane.

- The mechanic did not secure and lock out/tag out the propane stop valve (located at the engine). If the propane had been shut off, the explosion could not have occurred.

- The mechanic did not recognize the battery charger or the propane tank as secondary power sources and did not perform a zero energy check at the completion of the lockout/tagout. Although the mechanic removed the negative terminal from the battery, he did not realize that the battery charger was connected directly to the battery cable lugs and that the battery charger was supplying power to the engine.

- paraphrased from 2009-BNL-DF-0001 


\section{Module 3: Roles and Responsibilities}

\section{Module Objective}

When you have completed this module, you will be able to

- recognize the main roles and responsibilities of personnel involved with LO/TO at LANL.

\section{Roles and Responsibilities}

Primary roles associated with LANL LO/TO include

- authorized workers,

- lock coordinators,

- the equipment owner/operator,

- the RLM, and

- the FOD.

\section{Authorized Worker}

Note: ONLY authorized workers will perform maintenance and servicing of equipment that requires LO/TO.

The authorized worker has the following responsibilities:

- Works on equipment and machinery he/she has been trained on and authorized to work on by the FOD/designee. Verifies energy isolation from the equipment, and attaches a LANL HEC lock and tag provided by the FOD/designee.

- Notifies the owner/operator of the intent to apply a lock/tag to specific equipment BEFORE applying the lock/tag.

- Obtains authorization for LO/TO from the owner/operator, verifies energy isolation from the energy sources for the equipment, and affixes the HEC lock and tag before conducting work.

- Per P101-3, locks and tags equipment energy-isolating device(s) with a LANL HEC lock and tag on all equipment and machinery that could pose a danger to authorized workers and/or affected workers. 
- Maintains possession of the HEC lock's key during equipment maintenance or servicing.

- Removes ONLY his/her own HEC lock and tag when assigned work is complete.

- Removes his/her own lock if moved to another job. If he/she leaves the job for another reason, the equipment must be left in a safe condition, or the equipment must be locked out/tagged out by the owner/operator or the FOD/designee.

- Implements the LO/TO process in this procedure if the LO/TO authorized by the owner/operator or FOD/designee is for personnel safety as opposed to safety of the equipment or facility.

- Pauses or stops work if a component is not positioned correctly, a lock is not applied properly, a locking device is not applied appropriately, or a tag is missing. Barricades/closes the area to preclude access to the machine or equipment until the authorized worker contacts the appropriate supervisors/person in charge (PIC), RLM, and owner/operator to address the issue before continuing work. The owner/operator will contact other personnel as necessary to address and correct the issue.

\section{Lock Coordinators}

FODs may appoint one or more lock coordinators to assist in managing LO/TO. Lock coordinators have the following responsibilities within the facility:

- Maintain, issue, log, and account for locks.

- Serve as the FOD LO/TO point of contact for crafts.

- Maintain an accurate listing of equipment owners/operators.

- Approve as a designee of the FOD the Attachment B, Lockout/Tagout Orders.

- Ensure that Attachment B, Lockout/Tagout Orders, is completed properly before issuing locks.

- Ensure that Attachment A, Simple Energy Control Procedure, Lockout/Tagout (LO/TO) Tag, is filled out completely, correctly, and legibly.

- Complete the Remedy electronic log (see page 25).

- Support annual inspections as assigned by the FOD. 
The application of the locking device must NOT interfere with the authorized worker's ability to complete his/her required LO/TO steps.

\section{Equipment Owner/Operator}

The equipment owner/operator has the following responsibilities with respect to LO/TO:

- Is qualified to conduct LO/TO per P101-3, Lockout/Tagout for Hazardous Energy Control.

- Works with SMEs as needed to prepare instructions for placing equipment in the required configuration to support LO/TO.

- Marks the location of isolation devices per P101-3.

- Maintains equipment-specific LO/TO procedures and makes those procedures available to authorized workers.

- Approves the removal of equipment from service.

- Notifies affected workers when work is performed or approves authorized workers to make the notification.

- Approves specific written energy control procedures (SWECPS).

- Applies or works with FOD personnel to apply a locking device(s) and tag(s) to the energy-isolating device(s), if required, to maintain the safety of the workers from hazardous energy through control of the equipment and to ensure that post-maintenance testing is completed before the equipment is restarted.

- Helps authorized workers get locks, tags, and other devices from the FOD/designee.

- Takes action during a pause/stop work if a component is not positioned correctly, a lock is not applied properly, a locking device is not applied appropriately, or a tag is missing. Ensures that the authorized worker barricades/closes the area to preclude access to the machine or equipment until the owner/operator and the appropriate RLM address the situation and allow work to continue. Contacts other personnel as needed to address and correct the issue. 
Pause/stop work issues can include a component not positioned correctly, a lock not applied properly, a locking device not applied appropriately, or a missing tag.

\section{Responsible Line Manager}

The RLM has the following LO/TO responsibilities:

- Ensures that work is defined in enough detail to assess the risks and that LO/TO is used if the inadvertent release of hazardous energy could cause injury.

- Ensures that workers who perform LO/TOs are trained, knowledgeable of the equipment being locked/tagged, and follow the requirements of P101-3.

- Ensures that equipment- or machine-specific training at specific facilities is provided and that the record of training is maintained by the facility.

- Authorizes workers to perform LO/TOs.

- Ensures with the FOD that new and extensively modified programmatic equipment and machinery contain energyisolating devices designed to accept locks.

- Appoints a lead authorized worker as authorized by the owner/operator for group LO/TOs involving multiple workers from the same organization.

- Works with other RLMs, owners/operators, and the FOD/designee to ensure that a lead authorized worker is appointed for a group LO/TO involving multiple workers from different crafts, companies, and/or line organizations.

- Ensures that workers have HEC locks, tags, adapting devices, and other equipment necessary to complete work safely.

- Works to resolve pause/stop work issues identified by authorized workers. Ensures that the machine or equipment is barricaded or closed by the authorized worker to prevent accidental energizing by affected personnel.

- Using Attachment D, Authorization for Removing Locks and Tags for Energy Control Other Than Your Own, removes an authorized worker's HEC lock and tag if the worker is not available to remove his/her lock and tag, per P101-3.

- During shift and personnel changes, confirms continued personnel protection by ensuring that

- an SWECP is in place,

- the orderly exchange of locks and tags and orderly transfer of responsibility and task status from departing to arriving personnel is accomplished, and

- reverification of energy isolation is performed by arriving personnel. 


\section{Facility Operations Director}

The FOD has the following responsibilities with respect to LO/TO:

- Approves the application and removal of all locks/tags in his/her facilities.

- Designates, in writing, the owners/operators for all facility and programmatic equipment in his/her facilities and makes this list available to authorized workers who will be maintaining or servicing equipment in the facilities.

- Designates operations and/or facility and programmatic equipment that require independent verification. Provides authorized workers to perform independent verification as needed.

- Ensures annual review of LO/TOs in his/her facilities.

- Works with RLMs to appoint lead authorized workers.

- Ensures with the RLM that new and extensively modified facility equipment contains energy-isolating devices that accept locks.

- Provides locks, tags, and adapting devices to authorized workers.

- When operating under a variance in accordance with P101-3, conducts an annual review of the variance to determine its continued need.

Note: FODs may authorize tenants in their facilities to control specific LO/TO operations, but this action DOES NOT relieve FODs of the responsibility to effectively implement and maintain LO/TO in the facilities they control.

\section{Additional Roles}

Additional LO/TO responsibilities found in P101-3 belong to the

- LO/TO annual inspector,

- LO/TO program leader,

- deployed ESH manager, and

- associate directors for ESH and for Nuclear and High Hazard Operations. 


\section{Module 4: Lockout/Tagout Attachments and Procedures}

\section{Module Overview and Objectives}

LO/TO follows specific procedures that are documented with certain attachments. This module will help the user determine the procedures for LO/TO at LANL, which LO/TO documents are used for a given lockout activity, who completes the documents, the requirements for each document, and the recordkeeping requirements.

When you have completed this module, you will be able to recognize

- P101-3 attachments that are used for implementing and documenting LO/TO at LANL;

- the conditions that allow the use of a Simple Energy Control Procedure (SECP), and when an SWECP must be used;

- the steps for performing LO/TO at LANL; and

- $\quad$ the steps for releasing equipment from LO/TO.

\section{LANL Lockout/Tagout Attachments and Uses}

The table on the following page lists LANL LO/TO attachments to P101-3 and their uses. 


\begin{tabular}{|c|c|c|c|c|}
\hline \multicolumn{5}{|c|}{ Lockout/Tagout Attachments } \\
\hline Attachment & Use & Completed by & Requirements & Record Keeping \\
\hline $\begin{array}{l}\text { Attachment A, } \\
\text { Simple Energy } \\
\text { Control } \\
\text { Procedure, } \\
\text { Lockout/Tagout } \\
\text { (LO/TO) Tag }\end{array}$ & $\begin{array}{l}\text { Provides a visual } \\
\text { warning and } \\
\text { serves as a } \\
\text { written procedure } \\
\text { for simple energy } \\
\text { control. }\end{array}$ & $\begin{array}{l}\text { Authorized } \\
\text { worker }\end{array}$ & $\begin{array}{l}\text { Must be attached to } \\
\text { every red lock. } \\
\text { Must be attached to } \\
\text { every energy- } \\
\text { isolating device } \\
\text { when "tag only" } \\
\text { situations arise }\end{array}$ & N/A \\
\hline $\begin{array}{l}\text { Attachment B, } \\
\text { Lockout/Tagout } \\
\text { Orders }\end{array}$ & $\begin{array}{l}\text { Documents } \\
\text { specific written } \\
\text { procedure when } \\
\text { conditions for an } \\
\text { SECP are not } \\
\text { met. }\end{array}$ & $\begin{array}{l}\text { Authorized } \\
\text { worker(s), with } \\
\text { assistance of } \\
\text { SME and/or } \\
\text { equipment } \\
\text { owner/operator } \\
\text { as needed }\end{array}$ & $\begin{array}{l}\text { Must be used when } \\
\text { the conditions } \\
\text { required for using } \\
\text { an SECP are not } \\
\text { met. } \\
\text { Specific instructions } \\
\text { are included with } \\
\text { Attachment B. } \\
\text { A separate } \\
\text { procedure may be } \\
\text { written as long as it } \\
\text { includes all } \\
\text { information required } \\
\text { on Attachment B. }\end{array}$ & $\begin{array}{l}\text { Must be at the work site } \\
\text { when work is performed. } \\
\text { Must be with the work } \\
\text { package or contract } \\
\text { documentation for } \\
\text { subcontractor work. Must } \\
\text { be retained by the } \\
\text { owner/operator, } \\
\text { especially for repetitive } \\
\text { LO/TO activities }\end{array}$ \\
\hline $\begin{array}{l}\text { Attachment C, } \\
\text { LO/TO } \\
\text { Temporary } \\
\text { Paper Log }\end{array}$ & $\begin{array}{l}\text { Used if the } \\
\text { Remedy LO/TO } \\
\text { database is } \\
\text { unavailable. }\end{array}$ & $\begin{array}{l}\text { Facility } \\
\text { operations } \\
\text { director (FOD) } \\
\text { or designee }\end{array}$ & $\begin{array}{l}\text { Must be entered } \\
\text { into the Remedy } \\
\text { LO/TO database as } \\
\text { soon as practical. }\end{array}$ & $\begin{array}{l}\text { N/A after information has } \\
\text { been entered into the } \\
\text { Remedy LO/TO } \\
\text { database }\end{array}$ \\
\hline $\begin{array}{l}\text { Attachment D, } \\
\text { Authorization } \\
\text { for Removing } \\
\text { Locks and } \\
\text { Tags for } \\
\text { Energy Control } \\
\text { Other Than } \\
\text { Your Own }\end{array}$ & $\begin{array}{l}\text { Allows an RLM to } \\
\text { remove a lock } \\
\text { that he/she did } \\
\text { not attach. }\end{array}$ & $\begin{array}{l}\text { Responsible } \\
\text { line manager } \\
(\mathrm{RLM})\end{array}$ & $\begin{array}{l}\text { Must be available at } \\
\text { the work site while } \\
\text { the lock/tag is being } \\
\text { removed. } \\
\text { See P101-3 for } \\
\text { specific } \\
\text { requirements. }\end{array}$ & $\begin{array}{l}\text { Must be retained by RLM } \\
\text { of the organization } \\
\text { whose worker conducted } \\
\text { the lock removal for at } \\
\text { least one year. }\end{array}$ \\
\hline $\begin{array}{l}\text { Attachment E, } \\
\text { LO/TO Annual } \\
\text { Inspection } \\
\text { Process } \\
\text { Planning and } \\
\text { Data Collection } \\
\text { Form }\end{array}$ & $\begin{array}{l}\text { Assesses the } \\
\text { effectiveness of } \\
\text { the LO/TO } \\
\text { process, } \\
\text { adequacy of } \\
\text { specific LO/TO } \\
\text { procedures, and } \\
\text { the degree of } \\
\text { worker LO/TO } \\
\text { knowledge }\end{array}$ & $\begin{array}{l}\text { Facility } \\
\text { operations } \\
\text { director (FOD) } \\
\text { or designee }\end{array}$ & $\begin{array}{l}\text { See P101-3 for } \\
\text { specific } \\
\text { requirements. }\end{array}$ & $\begin{array}{l}\text { Must be maintained by } \\
\text { the FOD/designee for at } \\
\text { least four years. }\end{array}$ \\
\hline
\end{tabular}

*All LO/TO Orders, Authorization(s) for Removing Locks, and LO/TO Annual Inspection Form(s) associated with accident investigations will be retained until specifically authorized to dispose of the record by Laboratory Legal Counsel. 


\section{Lockout/Tagout Procedures-Simple or Complex Energy Control}

\section{LO/TO Tag \&}

Lock

\section{Simple Energy Control}

An example of an SECP is shown in Attachment A, Simple Energy Control Procedure, Lockout/Tagout (LO/TO) Tag. An SECP may be used when ALL of the following conditions apply:

- there is only one energy source,

- there is only one energy-isolating device that must be locked out to fully control the energy,

- the energy-isolating device is readily identifiable,

- the energy-isolating device can be locked,

- there is NO potential for stored or residual energy in the machine,

- NO shift or personnel changes will occur until work is completed,

- group lockout with multiple craft is not required, AND

- the FOD/designee does not require independent verification.

\section{Specific Written Energy-Control Procedure (SWECP)}

If an SWECP is needed, then the equipment owner/operator must work with the equipment/system owners/operators and SMEs as needed to ensure that the LO/TO will achieve a safe energy state for all involved workers.

If a hazardous energy assessment shows that an SECP cannot be used, an SWECP is required, including the use of Attachment B, Lockout/Tagout Orders. This may occur when the number of required isolation locations or devices, the complexity of the shutdown procedure, and/or other factors require additional information and approvals.

The equipment/system owner/operator gives guidance to workers performing the LO/TO, with help from other SMEs (as needed), to ensure that all energy sources and isolation devices are identified and that the equipment isolation is achieved. 


\section{Lockout/Tagout Procedure Steps}

\section{Plan the Work}

Once it is determined that LO/TO is required, the energy control procedure will explain what authorized workers must know and state what steps authorized workers must take to control hazardous energy during servicing and maintenance activities. At a minimum, the energy control procedure must contain enough detail for authorized workers to understand the controls and follow the steps for controlling all types and sources of hazardous energy associated with a work task.

Work planning must address the isolation of all sources of hazardous energy and the methods needed to safely relieve any stored hazardous energy before work begins.

This requirement may need workers or equipment/system operators to relieve, disconnect, restrain, drain, or otherwise render safe all potentially hazardous stored or residual energy in the machine or equipment. If hazardous energy can build up again, methods of preventing reaccumulation must be used and verification of the safe condition must be continual until the work is complete.

\section{Identify and Assess Hazardous Energy}

An energy assessment must be completed to find out how to address all the hazardous energy sources and the required controls. As part of the hazardous energy assessment, the equipment/system owner/operator must identify all hazardous energy source isolation points associated with the equipment or system upon which work will be performed. These energy sources and their energy-isolating device(s) must be identified, physically located, marked, and then controlled to prevent injury.

Isolation points may be labeled according to P315, Conduct of Operations Manual. Before work begins, any unlabeled isolation points must be labeled by the equipment or system owner/operator with a plain manila tag (or similar means) that has a unique identifier. The unique identifier must be written on Attachment A, Simple Energy Control Procedure, Lockout/Tagout (LO/TO) Tag, and entered into the Remedy LO/TO database in the "Energy Isolation Point" field. The temporary tag/label may be removed upon completion of the LO/TO. 
Contacting the owner/operator is an important step, especially when the owner/operator is located in another building but knows which personnel will be affected by the lockout.
Drawings, sketches, and system descriptions may be used to help identify isolation points but will not be relied on solely unless an isolation point or device is located in a hazardous environment that prevents safe entry. Where this is the case, an alternate isolation point, device, or render-safe procedure must be identified and documented.

The equipment/system owner/operator must conduct the energy assessment, identify isolation devices, and mark the isolation points for equipment/systems under his/her control or responsibility.

Note: Electrical safety officers (ESOs) can help during the planning and execution of LO/TO of electrical systems and equipment. A list of ESOs may be found on the Electrical Safety Program webpage.

In addition to protection from hazardous energy, an authorized worker, supervisor, or equipment/system owner/operator may apply a LANL red lock and tag to lock out equipment and machinery that could pose a danger to affected workers due to defect or damage. A manager who meets the requirements for an authorized worker may apply HEC locks and tags to equipment to protect affected workers.

Caution: The weight of the locks and locking devices could affect the structural performance and safety of some locked-out systems or components during a seismic event (earthquake). If the weight of the locking devices and locks exceeds 15 pounds, an evaluation from engineering must be obtained before the lock(s) and locking devices are applied. The use of a different locking device or use of group lockout (lock box) may avoid situations where the lockout equipment and locks may represent a seismic concern.

\section{Contact Owner/Operator}

Before applying the lock/tag, the equipment owner/operator (or group authorizing the LO/TO) must contact the personnel who will be affected by the LO/TO.

If LO/TO orders are needed, then the equipment owner/operator must work with the SMEs as needed to ensure that the LO/TO will achieve a safe energy state for all involved workers. 
"Devices" include locks, tags, and standard lockout devices. In some cases, special lockout devices may need to be obtained from the equipment owner/operator.
For more info on the Remedy LO/TO database, see the OSH LO/TO webpage.
The owner/operator who is LO/TO qualified may apply a HEC lock and tag to the energy-isolating device(s) to maintain control of the equipment for personnel safety and to ensure that postmaintenance testing or configuration is completed before the equipment is restarted.

Note: Owner/operator locking is NOT a substitute for authorized worker LO/TO of the equipment or system.

\section{Obtain LO/TO Device(s)}

The authorized worker(s) obtains the locks, tags, and isolating devices from the FOD's designated lock coordinator. The authorized worker must ensure that the energy-isolating device and the equipment or machine being controlled cannot be operated until the lockout device is removed. Locks must be securely attached to the energy-isolating device to prevent movement of the energy-isolating control to an unsafe position.

When needed, chains, wedges, key blocks, adapter pins, selflocking fasteners, or other specialized hardware for the lockout of a machine or system will be provided by the system/equipment owner/operator for the isolating, securing, or blocking of machines or equipment from hazardous energy sources.

The MSS webpage has a list of FOD contacts and information about recommended locking devices.

Remedy is a LANL LO/TO database that will be used by the FOD/designee(s) to authorize, issue, and record LO/TO activities at LANL. All LO/TO operations must be logged by the FOD/designee (usually a lock coordinator) in the Remedy LO/TO database before locks are issued and closed out when work is complete.

If the Remedy LO/TO database is not available, a paper log (Attachment C, LO/TO Temporary Paper Log) must be used until the Remedy LO/TO database becomes available. Locks recorded on the paper log must be recorded within Remedy as soon as practical. 


\section{Notify Affected Workers}

Whenever LO/TO controls affect another worker's work activities, the affected worker(s) must be notified. Affected worker(s) are notified by the equipment owner/operator, the authorized worker, or, where designated, the lock coordinator. ALL affected workers must be aware of the LO/TO before the equipment, machine, or system is shut down and before locks are removed and/or the machine or system is returned to service.

Depending on the number of affected workers, communication may be verbal, by e-mail, through the plan-of-the-day, etc. More than one method can be used, as long as ALL affected workers are made aware of the LO/TO.

\section{Shut Down Equipment}

The authorized worker must shut down the machine or equipment in accordance with the integrated work document (IWD), work package, standing or special order, or established procedure.

\section{Isolate and Lock Out Equipment from Energy Source}

The authorized worker must ensure that the energy-isolating device and the equipment being controlled cannot be operated until the lockout device is removed. He/she must place all energy-isolating devices in the appropriate position/condition to control all the hazardous energy to the machine in accordance with the IWD; established procedures; or Attachment B, Lockout/Tagout Orders.

If the authorized worker finds that the equipment or system cannot be effectively locked out with the devices provided, a pause or stop work must be declared until an effective device is found.

\section{Relieve Stored Hazardous Energy}

The authorized worker or owner/operator will relieve, disconnect, restrain, or otherwise render safe all potentially hazardous stored or residual energy in the machine or equipment. If the reaccumulation of hazardous energy is possible, then verification of the safe condition will be continual until the work is complete. 


\section{Verification:}

Location correct?

LO point correct?

Zero energy?

No reaccumulation?

Independent verification (IV) is only required in certain facilities and systems.

\section{Verify Zero Energy and Perform Verification}

Zero-energy verification should include checking that electrical systems show no voltage present (and grounding straps are attached, if applicable) and that fluid and pneumatic systems are depressurized and vented (or drained and flushed if applicable).

The authorized worker must verify that the steps used in the energy control procedure have effectively isolated the machine or equipment from the hazardous energy. If the authorized worker finds that the equipment or system cannot be effectively locked out with the devices provided, then he/she must pause the work until an effective device is found.

If verification is required, every isolation point must be verified. The authorized worker(s) must verify the isolation point(s) by comparing the hazard isolation point(s) identified by the authorized worker(s) with the isolation point(s) identified and marked by the equipment owner/operator (i.e., the tag, LO/TO order, and label).

When Attachment B, Lockout/Tagout Orders, requires verification, it is normally peer verification. However, independent verification (IV) may be required for some machines and equipment. The FODs are responsible for identifying those machines and equipment requiring IV, which must be noted on Attachment B, Lockout/Tagout Orders. More information on IV can be found in P315, Conduct of Operations Manual, Attachment 10, Independent Verification.

\section{Perform Work}

The worker must perform the work in accordance with the authorizing procedures. All workers must pause or stop work if they believe that hazards, controls, or quality are not effectively controlled. For more information, see P101-18, Procedure for Pause/Stop Work. 


\section{Restore Equipment to Service (Release from LO/TO)}

Note: If the work is complete but the worker will not be returning the equipment to service, he/she must notify the owner/operator before removing any locks and tags.

When service or maintenance is complete and the equipment is ready to return to normal operating condition, the authorized worker(s) must complete the following tasks:

- Check the equipment or machine and the immediate area to ensure that nonessential items that could result in damage or hazard have been removed and that the equipment or machine components are operationally intact.

- Check the work area to ensure that all workers have been safely positioned or removed from the area.

- Verify that the controls are in the neutral or "off" position.

- Notify the owner/operator and affected workers that the servicing or maintenance is done and that the equipment is ready to be released from LO/TO. Follow the instructions on Attachment B, Lockout/Tagout Orders.

- Remove the LO/TO device(s) and reenergize the equipment.

- Return the lock(s) and locking device(s) to the lock coordinator. 


\section{Lockout/Tagout Crosswalk}

\begin{tabular}{|c|l|l|c|}
\hline \multicolumn{4}{|c|}{ LO/TO Procedure Crosswalk } \\
\hline Step & \multicolumn{1}{|c|}{ New Procedure } & \multicolumn{1}{c|}{ Old Procedure } & Step \\
\hline 1 & Plan the work & $\begin{array}{l}\text { Identify \& evaluate hazardous } \\
\text { energies }\end{array}$ & 1 \\
\hline 2 & $\begin{array}{l}\text { Identify \& assess hazardous } \\
\text { energy }\end{array}$ & $\begin{array}{l}\text { Contact equipment } \\
\text { owner/operator }\end{array}$ & Obtain red locks \& tags \\
\hline 4 & Obtain the LO/TO device(s) & Notify affected workers & 2 \\
\hline 5 & Notify affected workers & Shut down equipment & 3 \\
\hline 6 & Shut down equipment & $\begin{array}{l}\text { Isolate equipment from energy } \\
\text { source }\end{array}$ & 5 \\
\hline 7 & $\begin{array}{l}\text { Isolate \& lock out equipment from } \\
\text { energy source }\end{array}$ & Lock out with locks \& tags & 6 \\
\hline 8 & Relieve stored energy & Relieve stored energy & 7 \\
\hline 9 & $\begin{array}{l}\text { Verify zero energy \& perform } \\
\text { verification }\end{array}$ & Verify safe condition & 8 \\
\hline 10 & Perform the work & Perform the work & 9 \\
\hline 11 & Release from LO/TO & Release from LO/TO & 10 \\
\hline
\end{tabular}




\section{Module 5: Lockout/Tagout Special Situations}

\section{Module Objective}

When you have completed this module, you will be able to recognize

- special situations that affect LO/TO at LANL.

\section{Lockout/Tagout Special Situations}

\section{If you CAN lock out, you MUST lock out!}

If using a tag only, you MUST take a second step that will give the same protection as using a lock, such as removing a fuse or valve hand wheel or breaking a line.
Special situations that affect LO/TO at LANL include

- tag only;

- group LO/TO;

- the use of lock boxes;

- $\quad$ the use of a single lock with multiple tags (rolling LO/TO);

- $\quad$ shift or personnel changes;

- confined spaces;

- vehicles and heavy equipment;

- temporary or partial removal of LO/TO;

- the removal of locks and tags other than your own;

- active lockouts of terminating/departing workers;

- LO/TO of equipment to prevent exposure to hazardous energy that is due to damage, defect, or noncompliance; and

- accidents, incidents, and off-normal or unusual events involving LO/TO.

\section{Tag Only}

Tags [Attachment A, Simple Energy Control Procedure, Lockout/Tagout (LO/TO) Tag] may evoke a false sense of security and will be used only when the energy-isolating device cannot physically be locked out. For any LO/TO at LANL, if an energyisolating device can be locked out, the authorized worker must use a lock rather than a tag-only option. 
If only a tag will be used, additional controls that provide worker protection equal to that provided by a locked energy-isolating device must be used. Examples of additional controls include the removal of valve handles, placement of barricades, and positioning of a person. The tag must be attached at the point where the lockout device would have been attached.

Note the following requirements for using the tag-only option:

- The FOD/designee must approve the use of a tag-only option.

- The tag must be entered into the Remedy LO/TO database, and the "unique number" (also called the "parent record") must be written onto the tag. When the tag is no longer needed and is removed, the tag must be brought back to the lock coordinator for closeout of the record within the database.

Note: If a tag becomes contaminated, dispose of the tag according to local procedures and then notify the lock coordinator so that the record can be closed out in Remedy.

- A tag attached to an energy-isolating device can be removed ONLY by the authorized worker who placed it. It must NEVER be bypassed, ignored, or otherwise defeated. If a tag placed by another person must be removed, Attachment D, Authorization for Removing Locks and Tags for Energy Control Other than Your Own, must be used.

- Tags must be securely attached to energy-isolating devices so that they cannot be inadvertently or accidentally detached during use.

- Tags must be clearly written and understandable.

\section{Group LO/TO}

Group LO/TO may be conducted using either simple LO/TO [Attachment A, Simple Energy Control Procedure, Lockout/Tagout (LO/TO) Tag] or complex LO/TO (Attachment B, Lockout/Tagout Orders). A lead authorized worker is appointed for group LO/TOs by

- the RLM when the workers are from the same craft, company, or organization; or

- the FOD/designee (with input from the RLMs) if the workers are from multiple crafts, companies, and/or organizations. 
Damage to an isolating device includes altering the seismic response of certain equipment.

Each lock box must be identified and recorded as a lockout point within the Remedy LO/TO database.
Rolling LO/TO requires

- co-located identical equipment with individual energy disconnect/isolation points, and

- simple energy controls
Attachment B, Lockout/Tagout Orders, must be used for multiple craft groups. The lead authorized worker will coordinate the activities of all members of the group, regardless of craft, company, or organization, to ensure continuity of protection and to ensure that a group lockout mechanism, such as a multi-lock hasp or lock box, is used if needed.

Each authorized worker must place his/her own lock and tag on the energy-isolating device. When an energy-isolating device cannot accept multiple locks and tags or when placing multiple locks could damage the isolating device, a lock box must be used (see below).

At least one authorized worker from a group must perform the verification step, but each authorized worker will observe and agree that the energy has been isolated from the equipment or machine and rendered safe.

\section{Lock Boxes}

When a lock box is used, the energy-isolating device(s) is/are locked/tagged out by the lead authorized worker, the key is placed in the lock box, and the lead authorized worker then places a lock on the lock box. The other authorized workers then place their locks on the lock box. Each authorized worker, including the lead authorized worker, must each have the one key to his/her specific lock in his/her possession. When the LO/TO event is completed, the LO/TO process is reversed. If the lock box cannot be left at the job site, it must be located with the lock coordinator for safekeeping.

Note: To prevent the key(s) in a lock box from being shaken out of the box, attach locks at the hasp position first.

\section{Using a Single Lock with Multiple Tags (Rolling LO/TO)}

A single lock may be used by a worker to conduct a sequence of simple lockout operations when conducting maintenance on colocated identical equipment having individual disconnects/isolation points. In such cases, the work is sequenced through the equipment by issuing a tag for each machine that the worker uses in conjunction with a single lock. This method of simple lockout is termed a rolling lockout/tagout. 
Blanking - the closure of a pipe or duct by fastening a solid plate over the bore.

\section{Shift or Personnel Changes}

LO/TO protection must continue when shift or personnel changes occur. This includes worker reassignment, end of shift, and/or transfer of work to another worker or crew. Such changes require the removal of locks and tags to allow the new worker or crew to place locks and tags on the energy-isolating device(s).

When shift or personnel changes occur, the lock coordinator(s) must update the Remedy database lock record to accurately document the changes made. If shift changes do not result in a change in workers, locks and tags may remain until the return of the worker or crew at the next scheduled shift.

Attachment B, Lockout/Tagout Orders, or the IWD or other work procedure must address how LO/TO protection will continue through shift or personnel changes by addressing how

- the exchange of locks and tags from departing to arriving personnel will be achieved (including updating the Remedy database and clearing the LO/TO instructions),

- arriving personnel will verify that the equipment is isolated and de-energized, and

- responsibilities and task status will be transferred from the departing to the arriving shift.

\section{Confined Spaces}

When LO/TO is required to isolate hazardous energy for work located in a confined space, OSHA 29 CFR 1910.146, PermitRequired Confined Spaces, requires fluid, gas, and steam to be controlled by at least two isolation methods, such as blanking or double block and bleed, before line breaking.

With mechanical energy, drive power systems will be locked out and the linkage between the drive and power transmission will be disconnected. For specifics, see P101-3.

\section{Vehicle and Heavy Equipment Maintenance}

LO/TO of vehicles and heavy equipment must be performed according to the manufacturer's instructions and safety information for mechanics. Vehicles must be prevented from starting, moving, or releasing hazardous energy stored in hydraulic systems, springs, and spring cans. In hybrid vehicles where the high-voltage battery must be disconnected, follow P101-13, Electrical Safety Program. For heavy equipment, stored hydraulic energy must be relieved and prevented from reaccumulating before work may be done on hydraulic systems. For specifics, see P101-3. 
ONLY RLMs can remove another's lock and/or tag, and they must use Attachment D.

\section{Temporary or Partial Removal of LO/TO}

Temporary or partial removal of a lock or tag is prohibited, unless it is required as part of an approved IWD, procedure, or Startup and Test Hazardous Energy Control Plan. If a lock or tag must be temporarily removed to test and/or position equipment, the authorized worker(s) must

- inspect the work area to ensure that all nonessential items that could cause a hazard have been removed;

- inspect the equipment/machine components to ensure they are operationally intact;

- ensure that all workers have been safely positioned or removed;

- ensure that each authorized worker removes his/her lock and/or tag;

- energize and proceed with testing or positioning; and

- deenergize, reapply energy control measures, and verify that isolation and deenergization of the equipment or machine have been accomplished.

\section{Removing Locks and Tags Other than Your Own}

No person may remove another's lock and/or tag unless the person who placed the lock/tag is off LANL property and unavailable. If this situation is substantiated, Attachment $\mathrm{D}$, Authorization for Removing Locks and Tags for Energy Control Other than Your Own, must be used to document the removal.

\section{Active Lockouts of Terminated/Departing Workers}

The first-line manager must ensure that when a worker terminates employment at LANL, any LO/TO involving the worker that is still active is either safely closed out or transferred to another worker. Workers who are leaving LANL must inform their supervisor of any LO/TO that is still active so that a safe restoration or transfer may take place. Workers MUST NOT remove locks on an active LO/TO to clear property requirements when departing LANL, without the express direction of their supervisor. 


\section{LO/TO of Equipment to Prevent Exposure to Hazardous Energy That Could Result from Damage, Defect, or Noncompliance}

Equipment/system owners and those responsible for operation or maintenance of equipment/systems are required to LO/TO equipment or systems that have been rendered a hazard due to damage, defect, or noncompliance with safety or inspection requirements. Such lockout(s) must remain until replaced by the lockout of workers engaged in

repairs,

render-safe procedures, inspection,

long-term inactivity protection, or

removal of the equipment.

Equipment/system owners must mitigate hazards posed by their equipment when notified by any worker that a hazard exists. For more information, see P101-3.

\section{Accidents, Incidents, or Off-Normal or Unusual Events Involving LO/TO}

All accidents, incidents, or off-normal or unusual events involving LO/TO must be reported in accordance with P322-3, Performance Improvement from Abnormal Events. The LO/TO program leader must be notified as soon as practical. 


\section{Module 6: Lockout/Tagout Applicability}

\section{Module Objective}

When you have completed this module, you will be able to recognize

- when LO/TO is NOT applicable, including work activities for which LO/TO requirements do not apply, sources that do not constitute hazardous energy requiring LO/TO, and other work where LO/TO might not apply.

\section{Activities for Which Lockout/Tagout Is NOT Applicable}

LANL LO/TO requirements do not apply to the following list of activities, each of which is explained below:

- cord-and-plug-connected electrical equipment;

- hot-tap operations;

- equipment and facilities that generate, transmit, and distribute electrical power;

- normal production operations where installed guards and/or safety devices and features are not removed or bypassed; and

- modes of electrical work addressed by P101-13, Electrical Safety Program.

\section{Cord and Plug}

LO/TO procedures do not apply to cord- and plug-connected electric equipment when

- unplugging the equipment from the energy source completely controls the hazardous energy, AND

- the plug is under the exclusive control of the employee performing the servicing and/or maintenance.

This exclusion applies to portable electric tools, as well as to cordand plug-connected equipment used at fixed locations. Once these items are unplugged, the responsible person cannot leave the area and leave the cord unplugged and unprotected. If the responsible person needs to leave the site, the plug must be capped (locked) and tagged to prevent inadvertent plugging in of the equipment or machine. 


\section{Hot-Tap Operations}

LO/TO procedures do not apply to hot-tap operations or welding involving transmission and utility distribution systems for substances such as gas, steam, water, and petroleum products when hot-taps are performed during the installation of connections and appendages on pressurized pipelines, vessels, and tanks. The Responsible Line Manager (RLM) of the organization performing the work will verify that continuity of service is essential, shutting down the system is impractical, and that accepted, documented procedures are followed. Hot-tap procedures will include the use of special equipment that provides effective protection for personnel.

\section{Electricity Generation}

Equipment and facilities that generate, transmit, and distribute electrical power and that are under the exclusive control of public utilities are not subject to industrial or construction LO/TO requirements. This includes related equipment for communication, control, and metering that is an integral part of an electrical utility generating plant, substation, or control center.

\section{Normal Production Operations}

Normal production operations of machinery and equipment, such as mechanical power presses, are not subject to LO/TO requirements. However, in these instances, the safety requirements of 29 CFR 1910, Subpart O, Machinery and Machine Guarding, apply. The servicing and maintenance of the equipment are excepted ONLY IF

- guards or other safety devices have NOT been removed or bypassed, OR

- a person does NOT have to place any part of his/her body in the point of operation or where a danger zone exists during the equipment operating cycle.

\section{Modes of Electrical Work as Defined by P101-13, Electrical Safety Program}

Modes of electrical work, as defined and covered by the requirements contained in P101-13, Electrical Safety Program, that require an Energized Electrical Work Permit (EEWP) executed by workers qualified as energized electrical workers.

Note: Requests to relax LO/TO requirements or use other methods must use the P101-3 variance request process (see P101-3). 


\section{Sources That Are NOT Considered Hazardous Energy}

Note: For additional guidance concerning a specific energy source and situation, contact local deployed ES\&H personnel or the LO/TO program leader.
The following examples of commonly encountered energy sources are NOT considered hazardous and DO NOT require LO/TO:

- Potable water at temperatures below $120^{\circ} \mathrm{F}$ and pressures less than 90 psi, where volumes that could be delivered (line size) do not present an engulfment, impact, displacement, or other associated hazard to the worker AND where the isolating valve is under the control of the worker(s).

- Electrical energy at 50 volts ac, 100 volts dc, and below where it is determined that there will be no increased exposure to electrical burns or to explosion due to electrical arcs.

- Compressed air at pressures 30 psig and below, where the isolating valve is under the control of the worker(s).

- Tubing or piping that serves inert gases at pressures 30 psig and below AND the volume/flow rate is such that oxygen displacement to $19.5 \%$ or less in the work space will not occur in less than 2 hours' flow AND where the isolating valve is under the control of the worker(s).

- Changing of inert, flammable gas, or oxygen gas cylinders serving equipment or manifolds, where each cylinder pigtail has a valve for isolation from the manifold.

Other types of work where LO/TO might not apply are listed below (for more information, see P101-3):

- Large scope Greenfield construction project sites designated as tagging authorities.

- Certain radiation protection work governed by P121, Radiation Protection, such as locked access ways, radiation interlocks, and other applications specified in P121 to require locks and interlocks.

- Emergency repairs of vital equipment, vendor SME assistance for critical LANL work, or other rare and short-period exceptional situations, as approved by the LO/TO program leader.

Note: A process exists by which organizations can request a variance to $P 101-3$ requirements. See $P 101-3$. 


\section{Module 7: Lockout/Tagout Training and Inspections}

\section{Module Objective}

When you have completed this module, you will be able to recognize

- the LANL LO/TO requirements for training and for periodic inspections of LO/TO at LANL.

\section{Lockout/Tagout Training}

Institutional LO/TO training requirements are shown in the table on the next page. Note the following specifics:

- Workers must complete course \#53493 initially and every 3 years thereafter, when their first-line manager or RLM determines that retraining is required because of skill deficiency or as indicated by annual inspection, and whenever there is a major revision to this procedure.

- Electrical worker training is also required for authorized workers who perform zero voltage checks/verification on electrical equipment and/or systems. Refer to training requirements in P101-13, Electrical Safety Program, Chapter 7, Electrical Worker Qualifications.

- To be authorized to conduct LO/TO and be issued locks and tags using the Remedy LO/TO database, authorized workers must be assigned to Curriculum (Training Plan) 127. 


\begin{tabular}{|c|c|}
\hline \multicolumn{2}{|r|}{ LANL LO/TO Training Requirements } \\
\hline If you are $a(n)$ & You must complete the following training: \\
\hline Authorized worker & $\begin{array}{l}\text { - Course } \# 53493, \text { Lockout/Tagout Live-initially and when } \\
\text { determined by the supervisor due to skill deficiency or when } \\
\text { indicated in annual inspection, whenever there is a major revision } \\
\text { to P101-3, and every } 3 \text { years. }\end{array}$ \\
\hline $\begin{array}{l}\text { Authorized worker who is an } \\
\text { energized electrical worker } \\
\text { authorized to conduct no } \\
\text { hazardous checks on } \\
\text { electrical equipment/systems }\end{array}$ & $\begin{array}{l}\text { - As above, plus } \\
\text { - } \quad \text { Authorized Workers conducting no hazardous checks: } \\
\text { chectrical worker training is required if performing zero voltage } \\
\text { See training requirements in P101-13, Electrical Safety } \\
\text { Program, Chapter 7, Electrical Worker Qualifications for more } \\
\text { information. }\end{array}$ \\
\hline Owner/operator & $\begin{array}{l}\text { - Course } \# 53493, \text { Lockout/Tagout Live, initially and when } \\
\text { determined by the supervisor due to skill deficiency as indicated } \\
\text { by annual inspection, whenever there is a major revision to P101- } \\
3 \text {, and every } 3 \text { years. }\end{array}$ \\
\hline $\begin{array}{l}\text { Facility operations director } \\
\text { (FOD) }\end{array}$ & $\begin{array}{l}\text { - Course \#30140, Lockout/Tagout for FODs \& RLMs Self-Study } \\
\text { Documented reading of P101-3 via UTrain initially and when } \\
\text { determined by the supervisor due to skill deficiency as indicated } \\
\text { by annual inspection, whenever there is a major revision to this } \\
\text { procedure, and every } 3 \text { years. }\end{array}$ \\
\hline $\begin{array}{l}\text { Responsible line manager } \\
\text { (RLM) }\end{array}$ & $\begin{array}{l}\text { - Course \#30140, Lockout/Tagout for FODs \& RLMs Self-Study } \\
\text { - Documented reading of P101-3 via UTrain initially and when } \\
\text { determined by the supervisor due to skill deficiency as indicated } \\
\text { by annual inspection, whenever there is a major revision to this } \\
\text { procedure, and every } 3 \text { years. }\end{array}$ \\
\hline
\end{tabular}

\section{Lessons Learned: Two Employees Killed, Five Injured by Hydrofluoric Acid Release}

A refinery hydrofluoric acid pump repressurized during motor replacement operations. An employee's confusion due to a lack of lockout procedures and training resulted in the unbolting of a pressurized hydrofluoric acid (HF) pump that was supposed to be depressurized. The pump containment failed, quickly releasing several hundred pounds of HF onto the unprotected employees. Employees \#1 and \#2 were killed, and Employees \#3 through \#7 were hospitalized. 


\section{Periodic Inspections}

Periodic LO/TO inspections must be performed annually by a LO/TO inspector designated by the FOD/designee. These inspections must follow P101-3 requirements and must assess

- the effectiveness of the LO/TO process,

- adequacy of specific LO/TO procedures used by workers, and

- the degree of worker LO/TO knowledge.

During these inspections, the FOD/designee must review and disposition locks hanging longer than 6 months but less than 1 year. The FOD must review and disposition locks hanging 1 year or longer. Additional responsibilities and requirements associated with annual inspections can be found in P101-3. 


\section{P101-3 Attachment A, Simple Energy Control Procedure, Lockout/Tagout (LO/TO) Tag}

\section{P101-3 Attachment A}

\section{( \\ DANGER DO NOT OPERATE}

\begin{tabular}{l|l}
$\square$ LANS Employee & Tag/Lock Number: \\
$\square$ Subcontractor &
\end{tabular}

Name (authorized person)

Phone Z\#

$\square$ Lead Authorized Person (check if designated as) Start Work Date Work Request \#

Work to be performed

Equipment Location: TA Bldg. $\quad$ Rm. Other

Equipment Description:

Energy-Isolating Device Location: TA Bldg. Rm. Other

Energy-Isolating Device:

Isolating Device Position for LOTO

Is this a simple lockout/tagout? $\square$ Yes $\square$ No

(Yes if)

there is only one energy source

- there is only one energy-isolating device that must be locked out to fully control the energy - the energy isolation device is readily identifiable

- the energy isolation device can be locked

there is no potential for stored or residual energy in the machine

- no shift or personnel changes will occur

- Group Lockout with multiple crafts not required

the Facility Operations Director (FOD)/designee does not require independent verification

If YES, follow the procedure on the back of this tag.

If NO, complete the following P101-3, Lockout/Tagout for Hazardous Energy Control,

Attachment B, Lock Out Tag Out Orders / Specific Energy Control Procedure FBRADY. BRADYID.COM

Made of $18 \%$ Post Consumer Waste

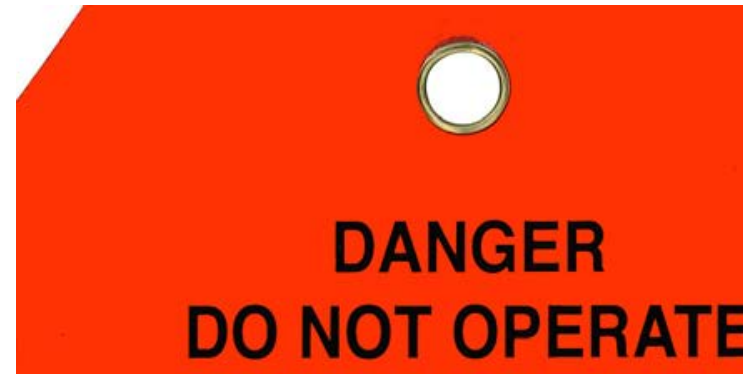

Simple Energy Control Procedure

1. Plan the work.

2. Identify \& Assess Hazardous Energy.

3. Contact the Equipment/System Owner Operator.

4. Obtain Locks and Tags from Lock Coordinator.

5. Have Affected Workers Been Notified?

6. Shutdown Equipment.

7. Isolate and Lock Out Equipment from Energy Source.

8. Relieve Stored Energy.

9. Verify Zero Energy and Perform Verifications.

10. Perform the Work.

11. Release Equipment from LO/TO.

\section{Release Equipment from LockoutTagout}

1. Check equipment and immediate area for items that could result in damage or danger on start-up.

2. Check the work area to ensure that all workers have been safely positioned or removed from the work area.

3. Verify controls are neutral or off position.

4. Notify the Owner/Operator and Affected Workers that work is complete and equipment is ready to release from LO/TO.

5. Remove the LO/TO device and re-energize.

6. Return lock, locking device to Lock Coordinator. 


\section{Attachment B: Lockout/Tagout Orders}

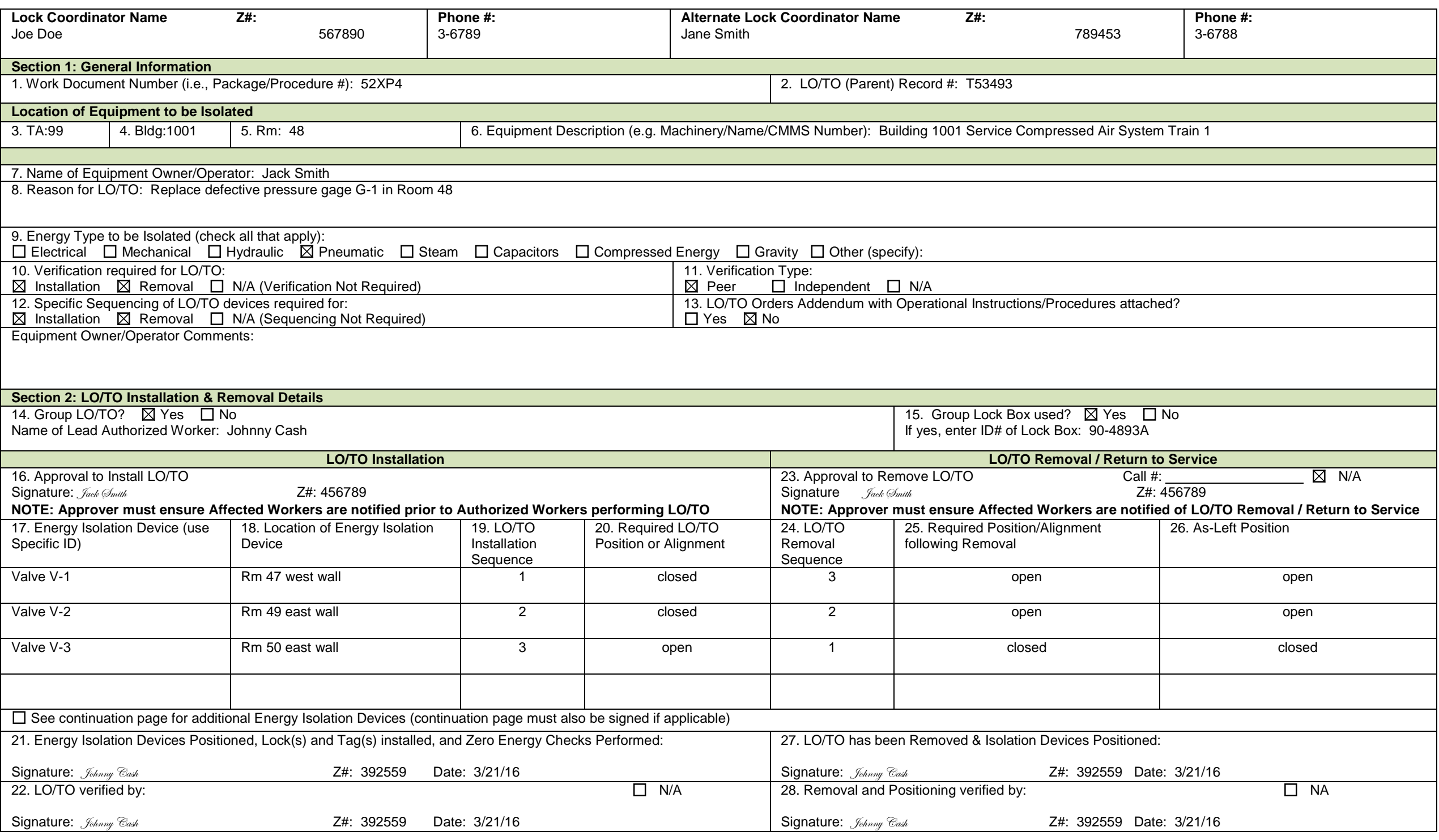




\section{Attachment B: Lockout/Tagout Orders}

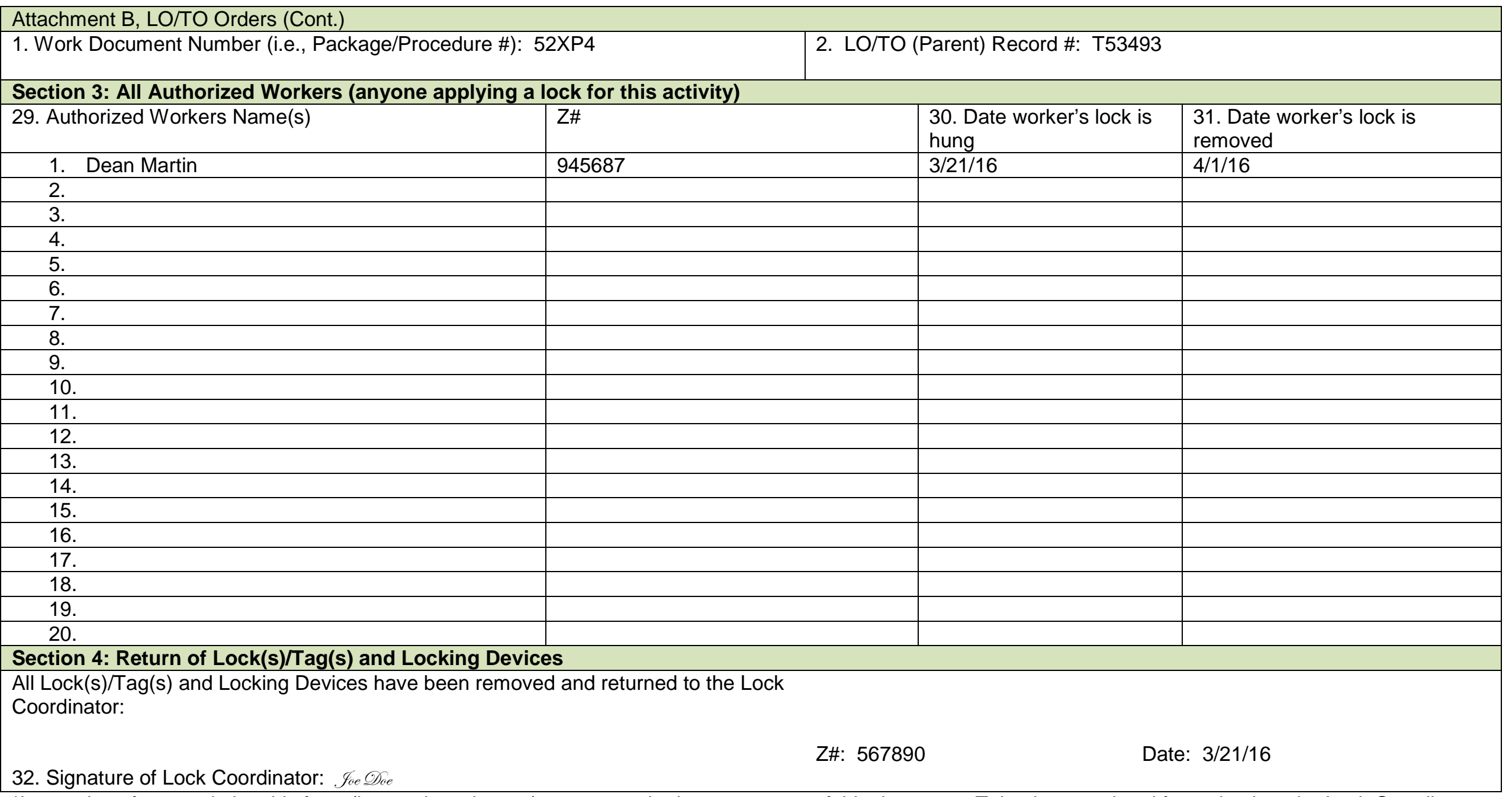

*Instructions for completing this form (by numbered steps) appear on the last two pages of this document. Take the completed forms back to the Lock Coordinator for closeout. 


\section{Attachment B: Lockout/Tagout Orders}

\section{Continuation Page (print as needed)}

\section{Attachment B, LO/TO Orders (Cont.)}

1. Work Document Number (i.e., Package/Procedure \#):

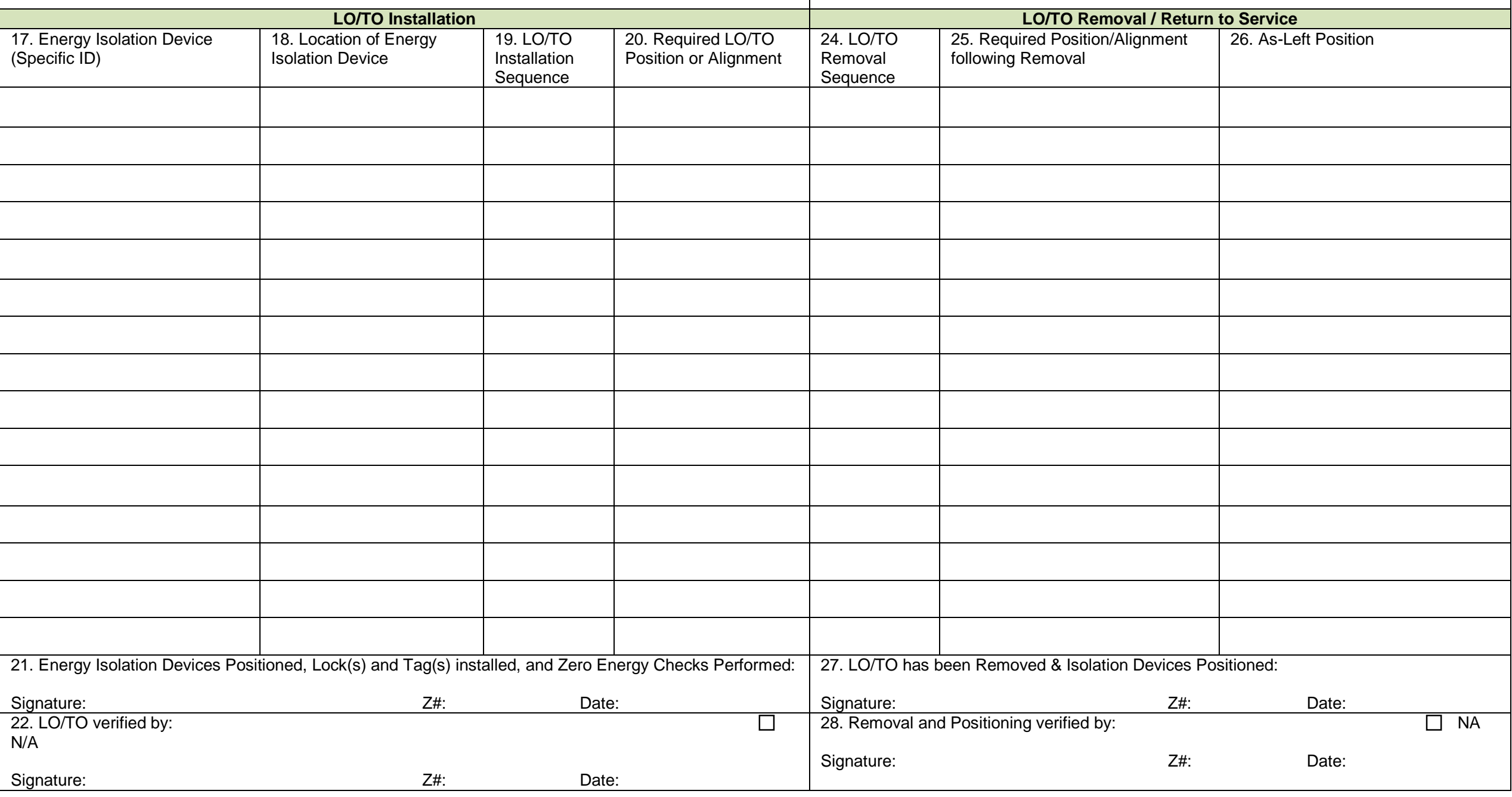

Lockout/Tagout for FODs \& RLMs Self-Study 30140 (LockoutTagout_FODsRLMs_30140_SS,R1.0) 


\section{Attachment B: Lockout/Tagout Orders}

\section{Instructions by Numbered Steps}

Lock Coordinator (Header): Identify the individual who will issue Red Locks to persons performing LO/TO (individual[s] identified by the FOD).

1. Enter the Work Document Number. This will be the number from the IWD or the procedure number (i.e., TA88-DOP-0001).

2. Enter the LO/TO Parent Record number. This is obtained from the Lock Coordinator when the lock(s) are issued. The Remedy LO/TO database generates this number.

3. Enter the TA where the equipment is located.

4. Enter the Building number where the equipment is located.

5. Enter the Room number where the equipment is located.

NOTE: Responses to steps 3 through 5 need to match information, identically, within both the LO/TO Orders and the tag (Attachment A).

6. Enter the Equipment/Machinery/Name/Number (example, HVA-001 [NOTE: LOG is to follow nomenclature contained within CMMS/MEL]).

7. Enter the Name of the Equipment Owner/Operator. The Equipment Owner/Operator is designated by the FOD. There may be both programmatic and facility Equipment Owner/Operators.

8. Write a brief description of the reason for LO/TO (example, removing and replacing exhaust fan belts).

9. Check the appropriate energy type to be isolated (check all that apply). Make sure you have considered all energy sources; if "Other" is checked, specify what "Other" is.

10. Is verification of the energy isolation configuration required for this LO/TO for installation and/or removal? Check the appropriate box(es). NOTE: Contact the FOD/Designee regarding verification requirements. Additionally, verification may be required by the Equipment Owner/Operator.

11. If verification is required, check the appropriate box (either "Peer" or "Independent"). If verification is NOT required, check the "N/A" box. NOTE: Independent verification may be required per P315, Conduct of Operations Manual, as determined by the FOD/Designee.

12. When installing the $\operatorname{lock}(\mathrm{s}) / \operatorname{tag}(\mathrm{s})$, is there a specific sequence in which the isolation devices are to be positioned? If a specific sequence must be followed for Installation and/or Removal, check the appropriate box(es) and subsequently identify the sequence order in column numbers 19 and/or 24 , accordingly. If there is not a specific sequence to follow, check the "N/A" box and place N/A in columns 19 and/or 24.

13. If an operating procedure/instruction/etc. is to be used in conjunction with the LO/TO Orders, check the "Yes" box and attach the pertinent document as an addendum. Additionally, a space is provided for Equipment Owner/Operator comments, if applicable.

14. Check either "Yes" or "No" to indicate if a Group LO/TO is applicable. A Group LO/TO is where two or more authorized workers, regardless of their occupation or craft, lock out and tag out the same equipment to perform servicing or maintenance. Enter the name of the Lead Authorized Worker.

15. Check either "Yes" or "No" to indicate if a Group Lock Box is to be used. If "Yes", enter the lock box ID\#. Each organization that issues locks will be required to uniquely number and track lock boxes in their possession.

16. The FOD-designated Equipment Owner/Operator signs and enters their Z\#, authorizing the installation of the LO/TO. The Approver is responsible to notify all Affected Workers prior to the Authorized Workers performing LO/TO ("Affected Workers" are those who either may work with the equipment or are affected by LO/TO activities).

17. Enter the specific energy isolation device/ID (e.g., MCC-A, A4). The ID used in the LO/TO orders must match information used on tag (Attachment A).

18. Location of energy isolation device (TA, Bldg, Rm, etc.). The location used in the LO/TO orders must match information used on tag (Attachment $A$ ). 


\section{Attachment B: Lockout/Tagout Orders}

19. If the LO/TO needs to be installed in a particular order (refer to Step \#12), number the sequence in which the locks need to be installed. If sequencing is not applicable, then place N/A in this column.

20. Required Position/Alignment for LO/TO (open, closed, connected, disconnected, on, off, etc.). Follow the nomenclature on the piece of equipment (e.g., if a service disconnect has "ON"/"OFF" posted, ensure the position/alignment entered on this form matches the piece of equipment ["ON" or "OFF"]).

21. The Lead Authorized Worker documents (signature) that the energy isolation devices have been positioned correctly, that locks and tags have been installed on those energy isolation devices and a Zero Energy Check has been performed.

NOTE: The Lead Authorized Worker may also be designated as the Person-in-Charge (PIC).

22. Is verification required (see \#10)? If verification is required, the person who performs the verification signs, and places their Z\# and the date here. If verification is not required, check the "N/A" box.

23. Documentation of Approval to Remove LO/TO. Equipment Owner/Operator or FOD Designee signs and places his/her Z\# in this box. Alternatively, authorization per telecommunication may be performed via a phone number identified for the Lead Authorized Worker to call the Equipment Owner/Operator or FOD Designee. Once verbal authorization is given, the Lead Authorized Worker documents the authorization as "per telecom" and enters his/her initials. Example: John Smith per telecom, JS. By checking the "N/A" box, a phone call is NOT REQUIRED by the Lead Authorized Worker to the Equipment Owner/Operator or FOD Designee.

NOTE: The Equipment Owner/Operator or FOD Designee is responsible to notify all Affected Workers after the LO/TO removal and of the equipment/machine's return to service.

24. If the LO/TO needs to be removed in a particular sequence (as per Step \#12), number the sequence in which the locks need to be removed. If the "N/A" box is checked in \#12, then place N/A in this column.

NOTE: Often the sequence for removal is opposite the sequence for installation. For example, if the order specified for installation Column \#19 is "1,2,3,4", the order specified for removal in Column \#24 could be "4,3,2,1". The intention of the LO/TO Orders is to have the entries in Column \#s 19 and 24 correspond with the energy isolation devices specified in Column \#17.

25. Identify the required position/alignment in which the system/component is to be placed following the removal of the lock(s). Follow the nomenclature as listed on the piece of equipment ("On", "Off", etc.).

26. Enter the As-Left Position.

27. The Lead Authorized Worker documents (signature, Z\# and date) that the locks and tags have been removed from the energy isolation devices and the energy isolation devices have been configured as per Equipment Owner/Operator specifications.

NOTE: The Lead Authorized Worker may also be designated as the Person-in-Charge (PIC).

28. If verification is required for the positioning, the person who performs the verification signs here. Otherwise, check N/A.

29. All authorized workers applying a lock for this activity (names/Z\#) must be documented. If more than 20 authorized workers are involved in a Group LO/TO, document the required information with an attached list.

30. Enter the date the authorized worker attaches his/her lock.

31. Enter the date the authorized worker removes his/her lock.

32. The Lock Coordinator or designee signs once locks, tags, and locking devices have been removed and returned. If a lock and/or tag are found to be contaminated, the lock and/or tag will be disposed of in accordance with local procedures and a verbal notification will be made to the Lock Coordinator to close out the record within Remedy. 